\title{
Vozes em aliança e vozes em confronto: a autoria nos domínios discursivos do processo de produção da publicidade contemporânea ${ }^{1}$ \\ Voices in alliance and voices in confrontation: the authorship in the discursive domains of the process of production of the contemporary publicity
}

Fábio Hansen²

Resumo A cadeia discursiva da publicidade atravessa uma fase de reconfigurações. O cenário de profusão de vozes, mesclado ao engajamento do consumidor nos processos produtivos em busca de autorrepresentação, transforma o fazer publicitário. É um fenômeno comunicacional que viola concepções previamente estabelecidas, dentre elas a noção de autoria aplicada à publicidade. Como perspectiva norteadora - tensionada à Análise de Discurso francesa, de orientação pecheutiana - tem-se o enfoque na ciberpublicidade como preâmbulo para examinar as condições de produção da narrativa publicitária. O reflexo da interatividade digital é o fortalecimento da autoria na dimensão do sujeito-consumidor. Palavras-chave: Autoria; Discurso publicitário; Criação publicitária; Sujeito-consumidor; Ciberpublicidade

\footnotetext{
Abstract The discursive chain of the publicity crosses a reconfigurations phase. The scenery of profusion of voices, blended to the consumer's engagement in the productive processes in search of self representation, transforms advertising behavior. It is a comunicacional phenomenon that violates conceptions previously established, among them the notion of applied authorship to the publicity. As a

${ }^{1}$ Versão modificada de trabalho apresentado no GP Publicidade e Propaganda do XV Encontro dos Grupos de Pesquisa em Comunicação, evento componente do XXXVIII Congresso Brasileiro de Ciências da Comunicação.

${ }^{2}$ Universidade Federal do Paraná - UFPR, Curitiba, PR, Brasil.

E-mail: fabiohansen@yahoo.com
} 
guiding perspective - tensioned to the French Analysis of Speech, of pecheut's orientation - the focus is in cyber-advertising as preamble to examine the conditions of production of the advertising narrative. As reflex of the digital interactivity strengthening the authorship to the subject-consumer's dimension.

Keywords: Authorship; Advertising speeches; Advertising design; Subject-consuming; cyber-advertising 


\section{Do consumidor virtual ao consumidor real, da presença ausente à poderosa presença}

A produção de sentido faculta uma interface entre consumo e discurso. Pêcheux (1993) define discurso como efeito de sentido entre interlocutores. Já Canclini (2005) compreende o consumo como conjunto de práticas socioculturais em que se constroem significados e sentidos. Martín-Barbero (2013), por sua vez, considera o consumo como produção de sentido.

É a essa noção mais ampla de consumo que nos filiamos, na sua dimensão simbólica. Não nos referimos a consumo em um sentido estreito de aquisição de produtos, em uma simples relação entre necessidades e os bens criados para satisfazê-las, em seus aspectos mercantis. O consumo, nas pegadas de Canclini (2005), ultrapassa a materialidade dos bens e envolve o consumo simbólico. Por extensão, não estamos abordando o consumidor de um determinado produto, na sua faceta econômica. Estamos pensando no consumidor do discurso publicitário, em um intercâmbio comunicativo entre autor e leitor, entre o sujeito publicitário e o sujeito consumidor da sua narrativa.

Tal entendimento se presta a refletir sobre a relação entre os profissionais de publicidade e o consumidor dos enunciados por eles criados, viabilizada convencionalmente via imaginário, pois é pela antecipação que o publicitário constrói o efeito-consumidor, constitutivo dos sentidos do seu dizer. Assim o sujeito-consumidor se atravessa por intermédio do imaginário no processo de produção do discurso publicitário, causando uma modificação de sentidos nas ideias criativas durante o processo, (re)adequadas a este consumidor projetado (HANSEN, 2013).

Deslocando um pensamento de Indursky (2001, p. 36) para a publicidade, diríamos que sob as ideias criativas do publicitário ressoam o seu interlocutor, que se assenta "sob a modalidade de uma presença ausente". No entanto, diante das transformações originadas pela mediação sociotécnica de dispositivos midiáticos (FAUSTO NETO, 2010), parece-nos que essa "presença ausente" se converte em uma poderosa 
presença, graças ao "novo espaço comunicacional" tecido de "conexões, fluxos e redes” (MARTÍN-BARBERO, 2014, p. 133).

A bibliografia, sob as mais diversas inclinações, atesta modos contemporâneos de interação, seja a Cultura da Convergência (JENKINS, 2008), a Cultura da Participação (SHIRKY, 2011), o Poder das Multidões (HOWE, 2008). Ato contínuo, a publicidade tradicional é impactada, bem como sua maneira de se relacionar com o consumidor da sua narrativa - não mais apenas o idealizado, silencioso, ausente. Tampouco a cadeia produtiva do trabalho publicitário fica imune, pois as condições de produção do discurso se alteram. O jogo do processo de criação publicitária tem seu espaço de (re)negociações e (re)formulações ampliado.

Pêcheux (1993), em 1969, foi quem introduziu a noção de condições de produção. Poderíamos definir, juntamente com Orlandi (1993) - que deu continuidade no Brasil à Análise de Discurso desenvolvida na França por Pêcheux -, condições de produção (CPs) como conjuntura abrangente de produção do discurso, que engloba o contexto histórico-social, a situação discursiva, os interlocutores, e o objeto do discurso. Para melhor compreender as vozes que se atravessam no processo de produção do discurso publicitário, nosso olhar recai em especial sobre os interlocutores, parte integrante das CPs propostas por Orlandi (1993) como circunstância que determina a produção do discurso.

Perante as inúmeras possibilidades de nomear o consumidor na ciberpublicidade (interlocutor, receptor, usuário, colaborador, compartilhador, prosumer, coprodutor, cocriador, coenunciador, amador, hiperconsumidor), amparamo-nos nas noções de leitor virtual e leitor real propostas por Orlandi (1993). O leitor virtual é aquele para quem um autor escreve e a quem atribui certos conhecimentos, opiniões, preferências, experiências. É o leitor projetado. Já os leitores reais são aqueles que efetivamente leem o texto. O leitor virtual é "um leitor que é constituído no próprio ato da escrita", a partir da imagem que o autor tem de seu possível interlocutor, que pode ser a imagem de um "cúmplice" ou de um "adversário" (ORLANDI, 1993, p. 9). 
O modelo de comunicabilidade em rede, interativo e conectivo, desloca esse cúmplice ou adversário da ordem do imaginário para a esfera do real, garantindo-lhe agora maior visibilidade e força presencial. O interlocutor se assume como real e não somente simbólico. Senão vejamos: o consumidor real se desdobra em duas ordens, o consumidor da estratégia (cúmplice) e o consumidor da resistência (adversário). Do ponto de vista da Análise de Discurso seria, respectivamente, o consumidor plenamente identificado e assujeitado; e o consumidor contraidentificado com o sentido dominante na comunicação publicitária. Ambos, assim como o consumidor virtual, constituem um consumidor-autor, porém com funcionamentos discursivos distintos.

Assim chegamos à autoria e ao seu caráter social, perspectiva que nos importa neste texto. Com as circunstâncias de produção do discurso publicitário ampliadas pela interatividade digital fortalece-se a autoria na dimensão do consumidor real. Conforme já fora demonstrado (HANSEN, 2013), o consumidor virtual já exerce a autoria, haja vista que, embora imaginário, é parte constitutiva do dizer. No cenário da ciberpublicidade o consumidor real também é alçado à condição de consumidor-autor, embora não se possa ignorar que ele já exercia a autoria mesmo antes das redes sociais digitais. Todavia, "as transformações recentes nos contratos comunicativos do discurso publicitário” (CASAQUI, 2014, p. 33) expandem não apenas a interlocução com os públicos aos quais são direcionados os enunciados publicitários, como também a circulação dos dizeres (tanto publicitários quanto dos consumidores da publicidade).

Assim sendo, a instabilidade e o caráter social dos sentidos revelam a premência de investigar a questão da autoria no domínio discursivo da publicidade. Portanto, é sob a égide da noção de autoria que aglutinaremos as discussões acerca das transfigurações do consumidor do discurso publicitário, manejando as desconcertantes hibridações narrativas que misturam as funções de leitura e de escrita, isto é, de leitor e autor. 


\section{Sujeitos e sentidos em movimento na ciberpublicidade}

Nosso objetivo é refletir sobre o sujeito-consumidor - constitutivo do sentido no processo de produção do discurso publicitário - que experimenta a autoria por intermédio de ambientes de interação que inauguram novos espaços discursivos. Julgamos ser imprudente mirar para os enunciados como produtos ignorando o processo de produção. Nesse sentido, abordamos a criação na publicidade sob uma perspectiva discursiva, como um complexo processo de produção de sentido, no qual o publicitário e o consumidor se fazem presentes como sujeitos. "Como olhar para os enunciados (como 'produtos') sem olhar para seus modos de enunciação (como a própria 'produção')?”, indaga Atem (2014, p. 128). Isso representaria ignorar os sujeitos que participam do labor dos enunciados.

É sabido que o sentido não é uma propriedade exclusiva do texto e de quem o produz. O sentido é fruto da interação dos leitores com os textos. De acordo com Martín-Barbero (2014) as mediações são o lugar de onde se outorga o sentido. Vale dizer, o efeito de sentido não se dá a priori, mas na condição de interação. "Produtores e consumidores de ‘textos' [...] participam da produção de significações e sentidos" (HARVEY, 2007, p. 55).

O processo da comunicação é ativo e interativo por natureza. A tecnologia, ao ofertar as condições técnicas para que os sujeitos cotejem significados, potencializa algo inerente ao ser humano, tendo em vista que, segundo Shirky (2011), os seres humanos são criaturas sociais que valorizam um sentido de conexão. A tecnologia remete hoje "a novos modos de percepção e de linguagem, a novas sensibilidades e escrituras" (MARTÍN-BARBERO, 2014, p. 79).

A lógica de interação credita uma expressividade inédita a um interlocutor contido, fazendo-o ingressar com crescente poder na arena da comunicação publicitária. São "novos diálogos que se estabelecem entre consumidores e anunciantes no âmbito das plataformas digitais" (COVALESKI, 2014, p. 157), reestruturando o contrato comunicativo na edificação do discurso publicitário. Cabe recordar, sucintamente, como 
se configura o sistema criativo publicitário. Acrescentamos, de imediato, que ele não está sendo substituído, mas expandido à luz do conceito de ciberpublicidade, que vem para tentar "mostrar suas continuidades e rupturas com o modelo tradicional de Publicidade” (ATEM, 2014, p. 138).

O consumidor virtual já interfere no processo de produção da comunicação publicitária via formação imaginária. Aqui convém mencionar Pêcheux (1993) e sua tese de que todo processo discursivo supõe uma antecipação das representações dos interlocutores, sobre a qual se funda a estratégia do discurso. A estratégia discursiva da antecipação prevê a possibilidade de respostas e dirige a argumentação publicitária, isto é, a ideia resultante do processo de produção do discurso publicitário só é veiculada a partir desta imagem construída, produzida por um gesto de interpretação do publicitário. É por estas antecipações imaginárias que o publicitário constrói o efeito-consumidor, projetando uma imagem homogênea em relação aos consumidores que compõem seu público-alvo.

Reconhecemos tal movimento de uniformização dos imaginários cotidianos como parte do funcionamento discursivo do sistema de produção da publicidade, que igualmente se vale de pesquisas junto ao público-alvo e de testes dos enunciados. No entanto, tais expedientes jamais afiançaram o controle dos sentidos. Na verdade, nunca passou de um efeito de controle, um esforço da publicidade tradicional na construção de uma realidade idealizada para o discurso publicitário.

Para Atem (2014, p. 132), "dos fluxos lineares da Publicidade tradicional, do anunciante para o consumidor, passamos aos fluxos mais circulares, ao modo dos diálogos", até então um efeito e que agora se estabelecem e tem continuidade a partir da manifestação dos consumidores repercutindo um discurso (publicitário) dos anunciantes, com direito a réplicas e tréplicas. O fluxo contínuo reflete uma incompatibilidade ideológica do consumidor real para com o consumidor virtual. Haja vista que o consumidor virtual é um imaginário do publicitário, o discurso publicitário circula e encontra inúmeros consumidores reais, diversos entre si, que efetivamente interagem com a comunicação 
publicitária e podem produzir uma interpretação que se afasta dos sentidos pretendidos.

Como resultado do distanciamento entre o consumidor virtual e o consumidor real, há o distanciamento entre o discurso pretendido pelos publicitários e o discurso efetivo no sujeito-consumidor. Em decorrência, a comunicação publicitária fica sujeita a uma avalanche de críticas e contestações, com agências e anunciantes tendo de se explicar de forma imediata porque agora "há novas vozes capazes de discursar e de serem ouvidas [...] novas possibilidades de interação entre consumidores e marcas; geradora de uma nova discursividade" (COVALESKI, 2014, p. 157).

\section{Resistência e estratégia: o consumidor real no discurso publicitário}

A nova realidade mercadológica amplifica uma voz já existente, a voz dos consumidores da comunicação publicitária. Verbos como curtir, comentar, compartilhar, rotular e avaliar indicam ações de um consumidor cada vez mais atento e crítico ao discurso publicitário, o que eleva a imprevisibilidade da interação. Jenkins (2008) relata que a participação do consumidor pode ser temida por alguns e acolhida por outros. O pensamento de Jenkins é útil porque nos conduz a um movimento duplo no campo publicitário: a resistência do consumidor ao discurso da publicidade, e a estratégia de aproximá-lo ao discurso publicitário. A resistência é proveniente dos sujeitos. Já a estratégia se origina nas corporações, incorporando o sujeito-consumidor.

Eis que identificamos um movimento de resistência, no qual os discursos são prioritariamente manifestações espontâneas dos consumidores e não das empresas; e igualmente um movimento estratégico de reinvenção do sistema publicitário, que estimula a produção entre profissionais e amadores. A abertura à participação pode ser compreendida como ameaça - institui-se uma relação de confronto (adversário) com os consumidores - ou como oportunidade - firma-se uma relação de aliança (cúmplice). 
Sob uma angulação, o setor publicitário percebeu que poderia incorporar a colaboração em suas estratégias, incentivando a participação do público na criação do discurso publicitário, e talvez tenha adotado tal comportamento em resposta ao discurso de resistência proveniente desse mesmo público. Dentre as tentativas para investir em um diálogo com os consumidores, destacamos a cocriação. Na ciberpublicidade o consumidor "é convocado a participar das campanhas, a coconstruir sua narrativa, a ser um coenunciador das marcas", diz Atem (2014, p. 131).

A cocriação vem da ideia de empresas trabalhando com sua cadeia de públicos, que pode incluir clientes, funcionários e fornecedores. No processo de criação publicitária, em particular, ela traz os consumidores para dentro do processo de geração de ideias. Cocriação, a título de ilustração, é o que foi feito no ano de 2013 pela agência Loducca com a Nextel quando anônimos inspiraram novos filmes publicitários da marca. Na verdade, foi mais do que inspirar. Pessoas comuns, necessariamente clientes Nextel, foram convidadas via internet3, na ação de relacionamento intitulada "Nextel: Conte sua História", a descrever uma história real relevante de sua vida. A narrativa, além de ser baseada em fatos verídicos de superação, não deveria fazer qualquer menção específica à Nextel, suas marcas, serviços e produtos. Diríamos que esse foi o briefing passado aos clientes da operadora, que poderiam participar voluntariamente. A ação tinha por objetivo escolher histórias reais para a comunicação publicitária da Nextel.

As histórias contadas por Juca Varella, Diego Reeberg, Ethel Rosenfeld, Fabiano Moreira, Juliana Motter, Fábio Leão e André Vianco foram selecionadas, produzidas e veiculadas. O personagem de cada comercial ajudava a escrever o roteiro, cocriando com a agência. Neste caso recente de estratégia publicitária fica evidenciada a criação participativa, na qual as pessoas de fora da publicidade auxiliam as agências na tarefa de criar, envolvendo-se e contribuindo ativamente.

A estratégia de cocriação produz vínculos afetivos e de sentido entre marcas e consumidores, instituições e sujeitos. Não obstante, por

\footnotetext{
${ }^{3}$ Nextel: Conte sua História. Disponível em: http://vc.nextel.com.br. Acesso em: 04 dez. 2015.
} 
intermédio dela tenta-se promover uma oxigenação na geração de ideias, uma vez que o processo pelo qual os publicitários criam é repetitivo e da ordem da reprodução (HANSEN, 2013), acarretando em um esgotamento criativo. Uma pessoa de fora tende a trazer um olhar diferente e abre caminhos para experimentação. A diversidade é o que defende Capote Filho (2014) ao argumentar que um grupo criativo heterogêneo olha o problema por diferentes pontos de vista, gerando hipóteses de respostas mais ricas.

Santaella (2013) observa que a solução colaborativa de problemas pelo trabalho conjunto de equipes resulta em processos de construção coletivos denominados processos de intercriatividade, redes de cooperação recíproca. A cooperação, no âmbito intelectual, para a criação de novas ideias provoca mudança na maneira de se pensar o processo de criação publicitária, afetando as relações de trabalho. Causa a impressão, precipitada, da terceirização do departamento de criação por parte das agências. A despeito da profusão de vozes, os consumidores estão, sim, produzindo em conjunto com os publicitários, mas sob a supervisão destes últimos, uma vez que são os profissionais de criação que compõe a versão final da comunicação publicitária. Desse modo, os publicitários são os curadores de ideias nas iniciativas de cocriação, responsáveis por dirigir o trabalho criativo, organizando-o e mantendo seu funcionamento.

Considerando que as pessoas nem sempre sabem como fazer para participar, os profissionais são indispensáveis a cada passo, assumindo a tarefa de gerenciar e dirigir a produção coletiva. Ao desempenhar a atividade de curadoria, o publicitário coordena os esforços dos participantes, em um trabalho de supervisão gerencial que zela pelos objetivos dos anunciantes. Na medida em que há uma produção formalmente gerenciada, poderíamos dizer, adaptando Casaqui (2014, p. 46), que o sujeito publicitário "constrói a lógica da transformação assumida como um fazer coletivo, no qual ele se coloca na posição de líder” do processo.

Nas situações de cocriação, como a da Nextel, o formato dos projetos colaborativos é planejado pelas agências em parceria com os 
anunciantes, e o conteúdo é criado pelo consumidor. Isso nos força a avançar na reflexão para demonstrar que a produção não se dá fora de práticas e rotinas profissionais. Ela não é amadora, ainda que o modelo envolva profissionais e não profissionais. Tampouco o esforço criativo dos consumidores amadores é livre, porque o sujeito do qual tratamos aqui é o sujeito da Análise de Discurso de orientação pecheutiana - não um sujeito livre, senhor de seus atos e de sua vontade, centro do seu dizer -, mas um sujeito social e descentrado, que sofre a intervenção do inconsciente e da ideologia. Logo, o sujeito-consumidor está assujeitado à formação discursiva em que está inscrito, dizendo apenas aquilo que ela permite e, consequentemente, a uma formação ideológica dominante. Dito de outra forma, está assujeitado à posição dominante relativa à publicidade e, por extensão, ao sentido dominante.

Ao examinar uma ação de cocriação não podemos ignorar que apesar da imersão no domínio temático do outro, a estratégia comunicacional não se afasta dos sentidos pretendidos pelo anunciante, mediado pelos profissionais de publicidade. É um estranho e novo híbrido que dá voz ao consumidor para seguir o que já está posto. Tanto que na edição das ideias quem assume o comando são os publicitários, editando em função do ponto de vista do anunciante, em um jogo enunciativo dissimulado.

A estrutura narrativa sobre a qual o consumidor trabalha e cria é estabelecida previamente pelos publicitários, em conformidade à trajetória do anunciante e de sua marca. Tal estrutura é mantida e respeitada, honrando a narrativa original. Desse modo, fica transparente o borramento de fronteiras entre os elementos internos e externos constituintes do discurso cocriativo. Todavia, a lógica interna prevalece, e os consumidores, como condição à participação, são confinados a uma experiência com um roteiro predeterminado, revela Shirky (2011). A criatividade "deixa voar, mas determina os procedimentos de descida. Em solo, obriga a passagem pela alfândega, é crítica e rigorosa, descarta ideias frágeis ou apenas belas e sem utilidade, pede mudanças" (CAPOTE FILHO, 2014, p. 130). 
A incorporação do consumidor aos processos produtivos é encarada por Casaqui (2014) como parte de uma estratégia publicitária de marcas que têm por palavra de ordem a convergência. Em seu olhar crítico, o autor sustenta que o sentido da coprodução compõe a lógica de contratos comunicativos, não passando de um "jogo dialógico" produto do “imaginário da construção compartilhada” (CASAQUI, 2014, p. 40). Acrescentaríamos que é o sistema publicitário se desenvolvendo ao assumir outras técnicas para o processo de criação, sem deixar, contudo, de recorrer a velhos procedimentos que escondem a verdadeira face das corporações. A interação, estrategicamente maquiada de horizontal, é absolutamente vertical. Considerando que "a cultura corporativa simula sua abertura à sociedade” (CASAQUI, 2014, p. 46), a sujeição se faz de modo mais sutil, transformando o sujeito-consumidor em um importante aliado na trama publicitária.

Em contraponto a horizontalidade camuflada, na qual "não se busca rupturas, mas sim confirmações, concordâncias, ausência de dissonâncias" (CASAQUI, 2014, p. 35), nasce um novo espaço discursivo, facilitador da expressividade de forma mais horizontal, característica da discursividade da ciberpublicidade. Essa nova dinâmica interacional está baseada não mais apenas na presença ausente de um consumidor imaginário, mas na poderosa presença de um consumidor real que não adere à estratégia e à convocação dos anunciantes para coproduzir o discurso publicitário. Desse modo, instaura-se a contraidentificação em relação à interação vertical e ao sentido dominante na narrativa publicitária e se instala a resistência.

Em contato com a publicidade, o consumidor-real-resistente desestrutura tudo aquilo que foi orquestrado pelos profissionais. Mais do que isso, ele interpela os anunciantes e não apenas é interpelado por eles, em um movimento pelo avesso. Esse fluxo inverso supera a estrutura tradicional do contrato comunicacional, de caráter indireto, pautado pela escassez de conversação entre os interlocutores. Com o advento da internet e das redes sociais digitais intensificou-se a intervenção direta e espontânea dos sujeitos nos campos pré-endereçados aos anunciantes em domínios eminentemente corporativos. 
Evidentemente a espontaneidade das manifestações dos consumidores deve ser examinada com reservas, pois o espontâneo pode estar inserido na estratégia publicitária, tática recorrente de anunciantes e de publicitários para angariar visibilidade por meio do discurso polêmico. Embora tenhamos dificuldade para aferir a espontaneidade em todas as situações de resistência a que temos acesso diariamente, não podemos por essa razão simplesmente negá-la. Proceder de tal modo (re)institui uma visão romântica a partir da ilusão de considerar que a publicidade é imune à contrapropaganda e a ter o seu saber colocado em confronto. Na perspectiva discursiva é impensável que o domínio do saber universal de determinada formação discursiva não seja posto em xeque, isto é, que o sentido dominante na formação discursiva publicitária jamais será desestabilizado mediante a colocação em xeque da sua ideologia. Se assim fosse, a formação discursiva não seria entendida como heterogênea.

Além de causar tensões, as intervenções não planejadas pelos anunciantes transportam, a reboque, prejuízos e inimigos às marcas das empresas anunciantes. É o que nos mostra, como unidade de estudo, a campanha de carnaval 2015 da Skol${ }^{4}$. A repercussão da frase "Esqueci o não em casa” presente nos anúncios não foi positiva e gerou contestações nas redes sociais digitais, repercutidas pela imprensa, depois que duas jovens - a publicitária e ilustradora Pri Ferrari ${ }^{5}$ e a jornalista Mila Alves - postaram fotos (figura 1) fazendo uma intervenção que alterava a mensagem original.

\footnotetext{
${ }^{4}$ Skol agora prega carnaval com respeito. Disponível em: http://www.meioemensagem.com.br/ home/comunicacao/noticias/2015/02/13/Apos-protestos-Skol-muda-pecas-de-carnaval.html. Acesso em: 6 dez. 2015.

5 Foi possível ouvir Pri Ferrari no evento "Vamos falar sobre gênero na publicidade?", promovido pelo Grupo de Planejamento e Atendimento do Paraná (GPAPR) no dia 19 de março de 2015. Disponível em: http://www.facebook.com/events/392828084224070. Acesso em: 5 dez. 2015.
} 

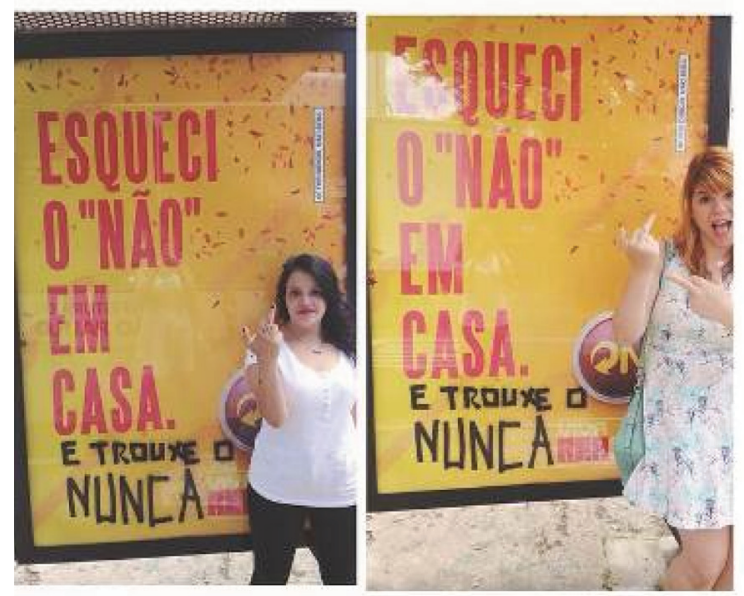

Segur - 11 die keneiero-Eutraso of

Wedazar vo instagram

4. "marzwilhosa" Skol daciniu fazer uma c.ampanha die

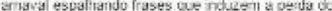

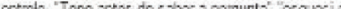

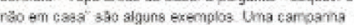
to:almente iresporsivd, prinsipalmente dxants o camaval que a gante sabe que o indice de astupm?

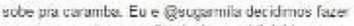
uma pequora irtanvenç tion Amigos pubieitínics. yer inseg

\section{Curir-Comeriar - Compardithar}

$G$ Dayana werera, Clansse Thles, Coca Ranaie vutss 28.446 pessoss cutramieso.

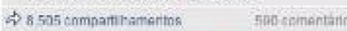
D) hisua zar comentâius unteriures

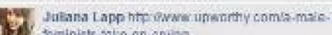

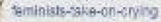

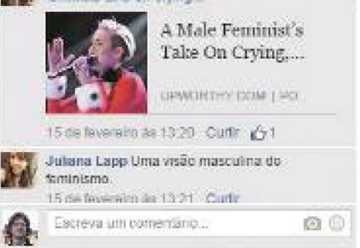

Figura 1. Facebook Pri Ferrari.

Fonte: http://www.facebook.com/priferrari22. Acesso em: 6 dez. 2015.

Como demonstra a imagem (Figura 1), o post teve 8.505 compartilhamentos, 590 comentários e 26.948 curtidas. Em razão da reprovação do seu conteúdo publicitário nas redes sociais, a Ambev alterou (Figura 2) as peças da polêmica campanha publicitária após a acusação de irresponsabilidade por fazer apologia ao estupro. A substituição do material publicitário foi divulgada pela empresa após a viralização nas redes sociais das queixas acerca do discurso publicitário. A Skol não apenas acatou o discurso dissonante do público, aceitando a presença deste interlocutor, como se apropriou do discurso dissidente para se explicar e justificar: "fomos alertados nas redes sociais que parte de nossa comunicação poderia resultar em um entendimento dúbio. E, por respeito à diversidade de opiniões, substituiremos as frases atuais por mensagens mais claras e positivas"

\footnotetext{
${ }^{6}$ Skol vai mudar campanha polêmica. Disponível em: http://www.meioemensagem.com.br/home/ comunicacao/noticias/2015/02/11/Skol-vai-mudar-campanha-polemica.html. Acesso em: 5 dez. 2015.
} 


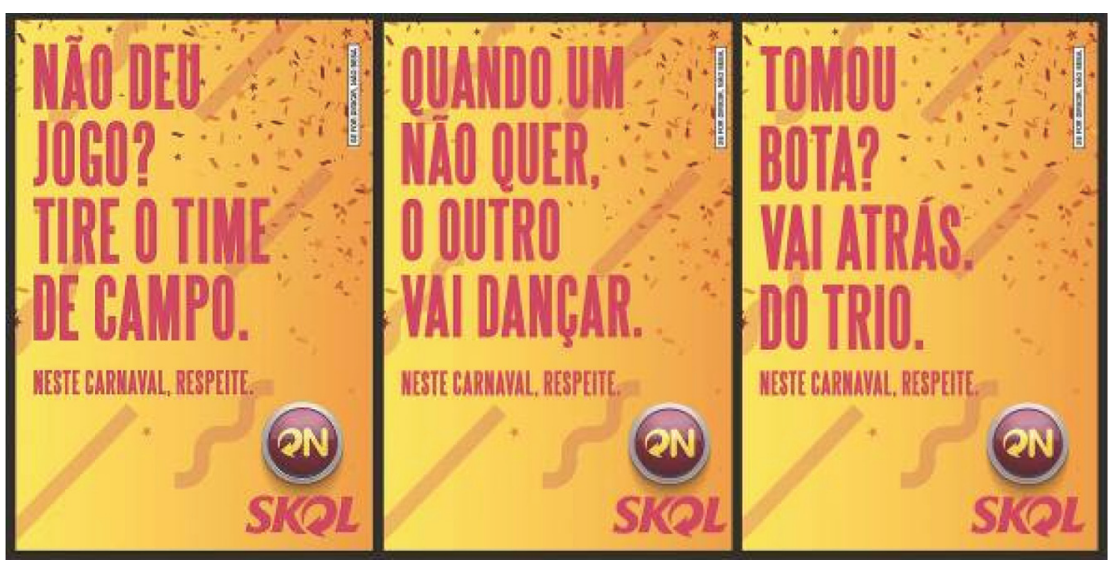

Figura 2. Novas peças publicitárias da comunicação da Skol Carnaval 2015. Fonte: http://www.meioemensagem.com.br/home/comunicacao/noticias /2015/02/13/Apos-protestos-Skol-muda-pecas-de-carnaval.html. Acesso em: 6 dez. 2015.

A fim de examinar o sujeito-consumidor no contexto contemporâneo das redes sociais digitais apresentamos o ocorrido no Carnaval 2015 com a marca Skol, fato que confirma a efervescência do fenômeno em tela. A repercussão negativa que surpreendeu os publicitários e a direção da empresa comprova a imprevisibilidade na comunicação e o descontrole dos sentidos atribuídos ao discurso publicitário pelo sujeito-consumidor em seu gesto de interpretação. À medida que se desconstrói e se desestabiliza uma superfície que parecia tão bem estruturada pela publicidade se institui o conflito entre o discurso pretendido pelos publicitários e o discurso efetivo no consumidor real.

O questionamento às marcas no ciberespaço atinge o ápice quando gera impactos distintos àquilo que estava previsto pelas estratégias de enunciação publicitária. Na situação relatada da Skol, outro fator ganha força: o imediatismo na comunicação. A resposta na web vem muito rápida, praticamente instantânea. A substituição da campanha aconteceu na mesma semana em que entrou no ar. Os participantes do mundo digital não só dão retorno real como modificam a forma e/ou o conteúdo em tempo real. Por conseguinte, o publicitário, que no modelo tradicional da publicidade era informado do eco produzido pelas enunciações nos 
consumidores e modificava paulatinamente suas pressuposições para futuros processo de criação, agora (re)organiza o dizer de imediato (figura 3, com destaque ao que marcamos em retângulo vermelho).
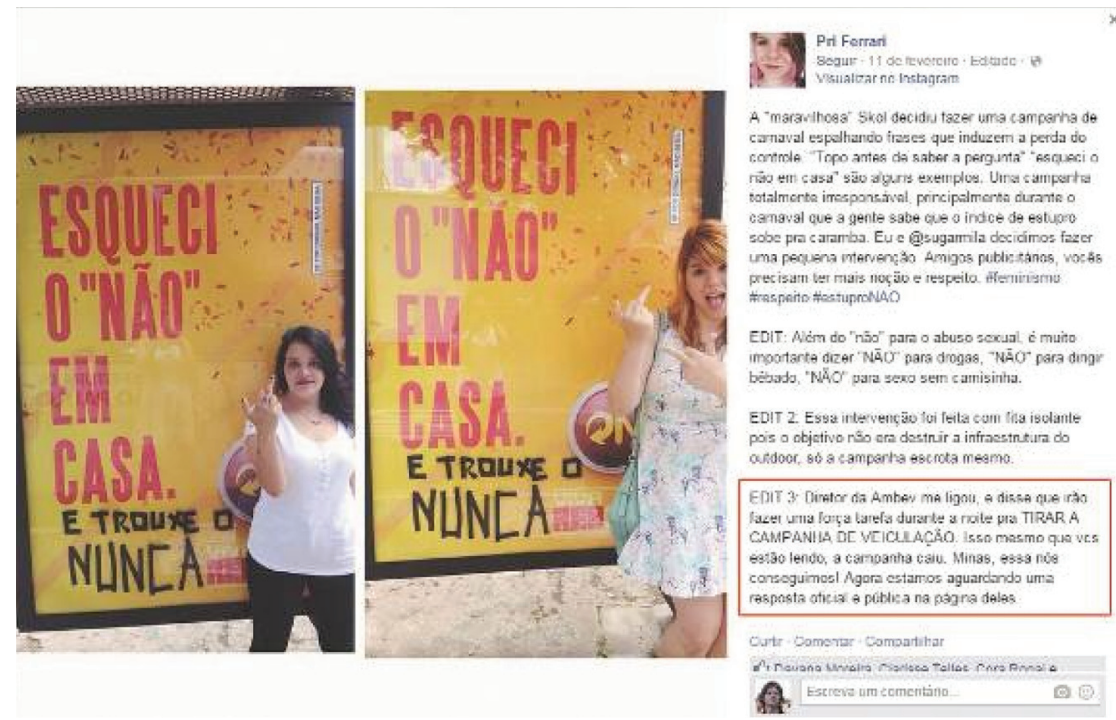

Figura 3. Facebook Pri Ferrari.

Fonte: http://www.facebook.com/priferrari22. Acesso em: 6 dez. 2015.

Ao fim e ao cabo, firma-se outra lógica para a confecção da comunicação publicitária, e em especial afeta as dimensões do trabalho em criação publicitária. No contexto da ciberpublicidade o produto do trabalho criativo é alterado quando já está "no ar" e não mais enquanto está em processamento. Eis uma modificação na mecânica de produção do discurso publicitário. Mudanças significativas de rota criativa são impostas com as interações já em andamento, com a campanha já em veiculação, aprovada e paga pelo anunciante.

Compreender esse movimento comunicacional publicitário a partir das mediações digitais, onde tudo é passível de ser prontamente rebatido e, por consequência, modificado, adaptado, transformado em tempo real e na velocidade que corre a internet, deveria estar no rol de (pre) ocupações dos anunciantes, das agências e dos profissionais; ainda mais 
que as repercussões em torno de campanhas são recorrentes e contundentes, refletindo na indústria da propaganda ao dar ao processo de criação um caráter ininterrupto.

Estes casos nos motivam a refletir sobre o fortalecimento da autoria na dimensão do consumidor real. Antes da revolução tecnológica dos últimos anos, o publicitário pouco ${ }^{7}$ interagia diretamente com este consumidor. Hoje, à medida que as redes sociais digitais permitem que as pessoas se expressem intensa, espontânea e instantaneamente, novos espaços discursivos e ambientes de interação foram criados, novos e mais sujeitos ocupam o lugar de autoria na produção do discurso publicitário, interferindo na geração de ideias, isto é, na movimentação dos sentidos no processo de criação da publicidade.

\section{A consolidação de um consumidor-autor no processo de produção do discurso publicitário}

Das práticas de interação na ciberpublicidade emergem vestígios de novas e mais vozes a experimentar a autoria no processo de produção do discurso publicitário. Juntamente com as demais vozes (anunciante, consumidor virtual, profissionais de atendimento, de planejamento, de criação, de mídia) que se atravessam no referido processo, os consumidores reais compartilham da autoria com todos os demais sujeitos. A despeito de ser algo que outrora já era possível, atualmente mostra-se com um funcionamento reconfigurado diante de uma situação discursiva modificada, na qual as formas relativas à interlocução são novas.

No processo de criação publicitária a autoria passeia entre os sujeitos como um lugar vazio a ser preenchido. Ou seja, eles estão autores, em um dado momento, em um dado lugar, porque a autoria é provisória

Ainda que seja da ordem da exceção - pois fora criada para provocar a resistência -, vale lembrar da comunicação publicitária da Benetton nos anos 1990. Pelos menos duas peças publicitárias da marca de vestuário despertaram reação social: um conjunto de outdoors que estampava a fotografia de uma mulher negra amamentando uma criança branca recebeu, em São Paulo, pichações populares com a frase de protesto "Mucama nunca mais". Já um outdoor que mostrava o beijo entre um padre e uma freira provocou protesto com bombas em loja da Benetton em Roma (AUGUSTO, 2004). 
(HANSEN, 2013). Ela é uma área de passagem, não de permanência. Flutuante, efêmera, fugaz, como um modo de estar autor, transferível a cada fase da criação. E agora outra fase de circulação e composição dos sentidos adquire novos contornos e maior importância: o veredito da reprovação ou o pedido de alteração da ideia que partiu dos publicitários é dado pelo consumidor real, não em pesquisas e grupos de discussão para testar, aprimorar ou descartar ideias, mas em tempo real e de modo recorrente.

Se, assim como o anunciante, o consumidor real possui poder de veto às ideias - um poder em tese da alçada das empresas - seja para desaprovar ou solicitar alteração, "proibindo-as" de permanecerem em circulação, naturalmente ele passa a ocupar um lugar de autoria, havendo transição na autoria. A partir do instante em que assume a responsabilidade pelo direcionamento dos sentidos, participando da exclusão de ideias - bem como da construção de outra(s) ideia(s) - o consumidor exerce pressão sobre o dizer publicitário.

A diferença, em comparação aos publicitários e ao anunciante, reside na etapa em que o consumidor da publicidade habita o lugar vazio da autoria: é com a comunicação publicitária na rua, em circulação, depois de aprovada - internamente - paga e veiculada. Ou seja, o job não sai da pauta, fica em stand-by porque a qualquer momento pode ser solicitada alguma alteração ou o material criado pode ser reprovado, mesmo já estando disponível para o consumo. Parece-nos que na comunicação publicitária contemporânea é diante dos olhos do grande público que o processo de produção dos enunciados se dá.

Presenciamos a dilatação do modo de produção do discurso publicitário e com ela o fortalecimento do consumidor-autor no processo de criação da publicidade. À medida que altera o sentido, e o responsável pelos desvios gera um novo sujeito-autor, o consumidor da narrativa publicitária é alçado a tal condição. Em todos os sujeitos envolvidos no job há uma instância de autoria, que passa de mão em mão, conforme a etapa discursiva, e em cada nova etapa a voz de um dos interlocutores se sobressai, fazendo nascer uma discursividade que traz consigo uma nova inscrição autoral. 
Pensar a questão da autoria implica estabelecer uma articulação com a interpretação. Estou considerando aqui, com base em Orlandi (1996), a interpretação como um irromper de efeitos de sentidos, tanto na produção como na leitura de textos, e a autoria como forma de articulação e deslocamento (maior ou menor) de sentidos em certa direção (MITTMANN, 2011, p. 100-101).

A autoria é uma intensa atividade de construção, desconstrução e reconstrução a qual o consumidor cada vez mais se incorpora. Toda vez que despontam intervenções do consumidor (sejam on-line ou off-line) irrompe um autor, impondo modificações significativas nas ações em andamento, apropriando-se da voz dos anunciantes e dos publicitários para (re)significar discursos e deslocar sentidos.

Evidentemente, estamos nos referindo ao consumidor real da ordem da resistência, da contraidentificação às regras tradicionais do jogo publicitário. Contudo, o consumidor real assujeitado à estratégia não foi desprezado. Muito embora, como já vimos, em circunstâncias distintas, ele também passou a galgar a condição de produtor de sentidos. A ressalva é que a cocriação discursiva é uma "atividade conjunta que encena sua vinculação ao ambiente corporativo” (CASAQUI, 2014, p. 47). Nem por isso o sujeito-consumidor inserido na estratégia de cocriação, atividade de produção híbrida e colaborativa, fica privado de questionar a noção tradicional de autoria como uma atividade puramente humana e notadamente individual.

No caso do processo de criação do discurso publicitário não há um autor exclusivo, a despeito de o efeito-autor fazer parecer que existe alguém responsável pela ideia criativa. Ao reconhecer a perspectiva de outros sujeitos que tornam o processo uma criação conjunta, a autoria é compartilhada, composta pelo cruzamento de diversos sujeitos-autores e, naturalmente, de saberes de diferentes espécies. Isso tudo nos conduz à noção de autoria coletiva, aquela que se propõe coletiva desde sua origem e que, no seu final, carrega conjuntamente a correspondência da função-autor ao efeito-autor (HANSEN, 2013). 
Na perspectiva da Análise de Discurso não há um grau maior ou menor de autoria. Isso desfaz qualquer cogitação sobre uma discrepância de autoria entre os dois tipos de consumidores reais. O consumidor assujeitado à estratégia vive sob a ilusão do empoderamento, tendo a sua produção narrativa moldada a partir do desejo das marcas e corporações. Por sua vez, o consumidor resistente à aceitação e à incorporação do discurso publicitário conduz a interação, e os sentidos nela produzidos, para além da estratégia e do pré-moldado, marcando o campo discursivo como território de disputas. Manifestações irrompem nas redes sociais digitais; com elas irrompe um autor e, igualmente, o modo de produzir adquire novos traços.

Não obstante em um haver assujeitamento pleno (identificação) e em outro contraidentificação (atuando em outra posição-sujeito e a ela assujeitado), em ambas as situações há autoria. Isso equivale a referendar a tríplice autoria (HANSEN, 2013), partilhada entre os profissionais da agência de propaganda, o anunciante e o consumidor - real e imaginário. Haja vista que os discursos se criam e se transformam também no universo digital, a autoria fica ainda mais diluída, absorvendo vozes em aliança e vozes em confronto.

A autoria não pode estar focada em somente uma das partes, seja o anunciante, os publicitários ou o consumidor. Ela está na dinamicidade da interação entre essas partes. Forma-se, assim, um intricado processo de autoria. Diante disso, mais do que justificar a afirmação de Mittmann (2011, p. 92) de que a autoria "se dá justamente no e pelo jogo da alteridade", nossa reflexão clarifica a noção de autoria difusa, compartilhada pela agência, pelo anunciante e pelo consumidor da enunciação publicitária, ou seja, os sujeitos envolvidos no processo de produção do discurso publicitário. Aos profissionais de criação publicitária cabe trabalhar no limite entre a própria autoria e uma autoria “outra”, assumindo uma cota de autoria.

Com as várias formas de fazer comunicação tomando forma, a atividade nas redes sociais digitais está reformulando a noção de autoria (GONTIJO, 2004). Nesse sentido, julgamos pertinente aproximá-la do 
sujeito-consumidor nos domínios discursivos da publicidade, pois as transformações mercadológicas, culturais e sociais operadas pela tecnologia nos encaminham a inquietações mais profundas a respeito de papéis previamente estabelecidos, incluindo aí a autoria. Desse modo, ao problematizar a reconfiguração por que passa o mundo do trabalho publicitário, esperamos que a argumentação aqui apresentada suscite novos debates, cumprindo assim nossa tarefa de investigar ações e movimentos de sentido que geram transformação na vida dos sujeitos e das instituições.

\section{Referências}

ATEM, G. N.; TAVARES, M. A. O pathos discursivo na Ciberpublicidade. In: ATEM, G. N.; OLIVEIRA, T. M. de; AZEVEDO, S. T. de (Org.). Ciberpublicidade: discurso, experiência e consumo na cultura transmidiática. Rio de Janeiro: E-papers, 2014.

AUGUSTO, C. Mobilização Social pela Propaganda: uma questão de ética. In: CONGRESSO BRASILEIRO DE CIÊNCIAS DA COMUNICAÇÃO, 27, 2004. Anais... Porto Alegre, 2004.

CANCLINI, N. G. Consumidores e cidadãos: conflitos multiculturais da globalização. 5. ed. Rio de Janeiro: UFRJ, 2005.

CASAQUI, V. Contratos comunicativos da comunicação publicitária contemporânea: sentidos da produção e do consumo nas estratégias de publicização. In: ATEM, G. N.; OLIVEIRA, T. M. de; AZEVEDO, S. T. de (Org.). Ciberpublicidade: discurso, experiência e consumo na cultura transmidiática. Rio de Janeiro: E-papers, 2014.

CAPOTE FILHO, H. S. Criatividade: o avesso do avesso, do avesso, do avesso. In: NICOLA, R. M. S. Ensaios sobre docência universitária. Curitiba: PUCPRess, 2014.

COVALESKI, R. O discurso do consumidor e a réplica do anunciante: identidade e alteridade nas plataformas digitais. In: ATEM, G. N.; OLIVEIRA, T. M. de; AZEVEDO, S. T. de (Org.). Ciberpublicidade: discurso, experiência e consumo na cultura transmidiática. Rio de Janeiro: E-papers, 2014.

FAUSTO NETO, A. Nas bordas da circulação. Revista Alceu, Rio de Janeiro, v. 10, n. 20, p. 55-69, jan./jun. 2010.

GONTIJO, S. O livro de ouro da comunicação. Rio de Janeiro: Ediouro, 2004.

HANSEN, F. (In)verdades sobre os profissionais de criação: poder, desejo, imaginação e autoria. Porto Alegre: Entremeios, 2013.

HARVEY, D. Condição pós-moderna. São Paulo: Loyola, 2007. 
HOWE, J. O poder das multidões: por que a força da coletividade está remodelando o futuro dos negócios. Rio de Janeiro: Campus, 2008.

INDURSKY, F. Da heterogeneidade do discurso à heterogeneidade do texto e suas implicações no processo da leitura. In: ERNST-PEREIRA, A.; FUNCK, S. B. (Org.). A escrita e a leitura como práticas discursivas. Pelotas: Educat, 2001.

JENKINS, H. Cultura da convergência. São Paulo: Aleph, 2008.

MARTÍN-BARBERO, J. Dos meios às mediações: comunicação, cultura e hegemonia. 7. ed. Rio de Janeiro: Editora UFRJ, 2013.

MARTÍN-BARBERO, J. A comunicação na educação. São Paulo: Contexto, 2014.

MITTMANN, S. Texto imagético e autoria. In: INDURSKY, F.; MITTMANN, S.; FERREIRA, M. C. L. Memória e história na/da Análise do Discurso. Campinas: Mercado de Letras, 2011.

ORLANDI, E. Discurso e Leitura. 2. ed. São Paulo: Cortez; Campinas: Editora da Unicamp, 1993.

ORLANDI, E. Interpretação: autoria efeitos do trabalho simbólico. Petrópolis: Vozes, 1996.

PÊCHEUX, M. Análise Automática do Discurso. In: GADET, F.; HAK, T. (Org.). Por uma análise automática do discurso: uma introdução à obra de Michel Pêcheux. 2. ed. Campinas: Unicamp, 1993.

SANTAELLA, L. Intersubjetividade nas redes digitais: repercussões na educação. In: PRIMO, A. A internet em rede. Porto Alegre: Sulina, 2013.

SHIRKY, C. A cultura da participação: criatividade e generosidade no mundo conectado. Rio de Janeiro: Zahar, 2011.

\section{Sobre 0 autor}

Fábio Hansen - Professor adjunto no departamento de Comunicação Social da Universidade Federal do Paraná, onde coordena o curso de Comunicação Social, e docente permanente no Programa de Pós-Graduação em Comunicação (PPGCOM-UFPR) na linha de pesquisa Comunicação, Educação e Formações Socioculturais.

Data de submissão: 07/12/2015

Data de aceite: 20/05/2016 